\title{
Síndrome de tremor e ataxia associada ao X frágil: rastreamento por PCR em amostra de idosos
}

\author{
Fragile X-associated tremor/ataxia syndrome: \\ PCR-based screening in a sample of elderly men
}

Denise Maria Christofolini', Fernando Santos Pinheiro', Bianca Bianco', Maria Isabel Melaragno², Marco Antonio de Paula Ramos², Décio Brunoni², Flavio Geraldes Alves', Caio Parente Barbosa'

\begin{abstract}
Resumo
Introdução: A presença de sequências repetidas de DNA já foi identificada como marcadoras de certas doenças neuropsiquiátricas. 0 gene FMR1 possui sequência rica em repetições CGG, sujeito a expansão quando transmitido por via materna. Alelos pré-mutados $(55<C G G<200)$ são instáveis e podem se expandir para mutações completas (>200 repetições CGG). Na mutação completa, o gene é inativado determinando a síndrome do X frágil (FRAX). Os portadores da pré-mutação não apresentam deficiência cognitiva associada à FRAX, porém, um subgrupo desses indivíduos com mais de 50 anos de idade desenvolve uma síndrome neurológica progressiva, a síndrome de tremor/ataxia associada ao X frágil (Fragile X-associated Tremor/ Ataxia Syndrome-FXTAS). Objetivos: Este estudo investigou as características clínicas e moleculares dos familiares de quatro homens com mais de 50 anos de idade, familiares de indivíduos FRAX, uma vez que esses indivíduos possuem risco elevado de desenvolver o quadro de FXTAS. Resultados: Nenhum dos pacientes avaliados possuía FXTAS. Conclusão: A síndrome FXTAS foi recentemente descrita e é pouco conhecida no meio clínico e científico. Dessa forma, a avaliação de familiares de indivíduos FRAX pode contribuir para o melhor entendimento da doença e permitir a determinação de sua incidência na população brasileira.
\end{abstract}

Palavras-chave: FXTAS, Síndrome do cromossomo X frágil, Expansão das repetições de trinucleotídeos, Doenças genéticas ligadas ao cromossomo X, Proteína do X frágil de retardo mental, Manifestações neurológicas.

\begin{abstract}
Introduction: The presence of repeated sequences was already identified as markers of neuropsychiatric diseases. The FMR1 gene shelters a CGGrich sequence which is vulnerable to expansion when transmitted through maternal lineage. Premutated alleles $(55<\mathrm{CGG}<200)$ are unstable and can expand to full mutations (> 200 CGG repeats). In the full mutation range, the gene is inactivated causing the fragile $X$ syndrome (FRAX). Premutation carriers do not present mental retardation, however a subgroup of permutation carriers older than 50 years can develop a progressive neurological syndrome, the Fragile X-associated Tremor/Ataxia Syndrome (FXTAS). Objectives: This approach had investigated clinical and molecular features of four males - relatives of FRAX individuals - due to the high risk of developing FXTAS. Results: None of the investigated patients had FXTAS. Conclusion: This syndrome was recently described and there is little knowledge about it by clinicians and scientists. Thus, evaluation of people in this condition can contribute to the better understanding of the disease and its incidence in the Brazilian population.
\end{abstract}

Keywords: FXTAS, Fragile X syndrome, Trinucleotide repeat expansion, Genetic diseases, X-linked, Fragile X mental retardation protein, Neurological manifestations

Recebido: $24 / 11 / 2008$

Revisado: $13 / 3 / 2009$

Aprovado: 6/4/2009

Faculdade de Medicina do ABC (FMABC), Santo André (SP)

2 Universidade Federal de São Paulo (Unifesp), São Paulo (SP)

Endereço para correspondência: Fernando Santos Pinheiro - Avenida Lauro Gomes, 2.000 - CEP 09060-870 - Santo André (SP) -

E-mail: fernandocanada@hotmail.com 


\section{Introdução}

Os distúrbios neuropsiquiátricos herdados são motivo de grande interesse na medicina. A análise do genoma de pacientes com esses distúrbios tem ajudado a revelar as complexidades e as similaridades no que diz respeito à sequência do DNA. Em certas doenças neuropsiquiátricas, foram identificadas sequências repetidas de DNA que funcionam como marcadores das mesmas ${ }^{1}$. Essas sequências podem aumentar em tamanho com o passar das gerações, um fenômeno denominado antecipação². Até o momento, já foram identificadas sequências distintas, envolvidas no processo de expansão, relacionadas aos diferentes distúrbios neuropsiquiátricos, como CAG, CUG, CCG, entre outras.

Em 1991, Oberlé et al. ${ }^{3}$ identificaram uma sequência instável e expansível de trinucleotídeos CGG na região não traduzida (untranslated region - UTR) 5' do gene FMR1 (Fragile X Mental Retardation 1), responsável pela síndrome do $X$ frágil, a causa mais comum de deficiência mental herdada ${ }^{4}$.

Esse gene, localizado no braço longo do cromossomo X (Xq27.3), codifica pelo menos 12 tipos distintos de RNAm originados pelo mecanismo de splicing alternativo, com expressão em diversos tecidos, em especial no cérebro, testículos e epitélio. A proteína resultante da expressão desse gene denomina-se FMRP (Fragile X Mental Retardation Protein) ${ }^{5}$.

$\mathrm{O}$ alelo normal do gene FMR1 possui entre 6 e 54 repetições de trinucleotídeos CGG. Na presença desse alelo, ocorre produção normal da proteína FMRP e fenótipo normal. Os alelos com mais de 200 repetições, conhecidos como mutações completas, determinam a síndrome do X frágil. A presença da mutação leva à inativação do gene FMR1 decorrente da metilação na região promotora e, consequentemente, ausência de FMRP ${ }^{4,6}$.

Na faixa entre 55 e 200 repetições CGG estão os alelos pré-mutados. Tais alelos são instáveis e podem expandir para mutações completas quando transmitidos por via materna; o risco de expansão para a mutação completa na próxima geração está diretamente relacionado ao tamanho e à ausência de sequência AGG na pré-mutação ${ }^{4}$. Essas trincas AGG interrompem a sequência de trincas a cada nove ou dez conjuntos CGGs; a perda dessas trincas pode induzir um aumento no conjunto de trincas CGG não interrompidas, levando ao escorregamento da polimerase, fenômeno também conhecido como DNA slippage.

Em 2001, Hagerman et al. ${ }^{7}$, a partir da observação de sinais e sintomas clínicos manifestados por avôs maternos de crianças com FRAX, descobriram uma nova síndrome causada pela pré-mutação do gene FMR1. Nesses indivíduos, observou-se um distúrbio neurológico progressivo, o qual denominou Síndrome de Tremor/Ataxia associada ao X Frágil (FXTAS, Fragile X-associated Tremor/Ataxia Syndrome) ${ }^{7}$.

Os aspectos clínicos da FXTAS no sexo masculino envolvem tremor de intensão e ataxia motora que, geralmente, iniciam-se após os 50 anos. Outras características podem estar presentes como a neuropatia periférica, o quadro de parkinsonismo, disfunções autonômicas como hipotensão ortostática, impotência, incontinência fecal e urinária além de deficiência cognitiva gradual, começando com perda de memória e diminuição das funções executivas. Características psiquiátricas como ansiedade, desinibição, instabilidade de humor, depressão e apatia também são problemas comuns ${ }^{8}$.

$\mathrm{O}$ início dos sintomas cognitivos foi notado pelos pacientes durante idade média de 60 anos. O tremor foi referido por volta dos 58 anos ( \pm 4 anos) e ataxia, com idade média de 62 anos ( \pm 6 anos). Os achados de ressonância magnética em pacientes com FXTAS incluem atrofia cerebral global e dilatação dos ventrículos. Além disso, revelaram-se aumentos aproximadamente simétricos na intensidade do sinal na ponderação $\mathrm{T} 2$ nos pedúnculos cerebelares médios e substância branca adjacente. $\mathrm{O}$ mais característico achado neuropatológico associado à FXTAS é a presença de inclusões intracelulares eosinofílicas tanto nos neurônios quanto nos astrócitos. Essas inclusões encontramse por toda a córtex e tronco cerebral, sendo que inclusões de densidades mais acentuadas localizam-se no hipocampo e regiões da córtex frontal ${ }^{9,10,11,12}$. As mulheres também apresentam FXTAS, embora a alteração no movimento seja menos comum, provavelmente devido ao efeito protetor do cromossomo X normal.

A prevalência da pré-mutação foi estimada em 1:800 homens e 1:250 mulheres ${ }^{12}$. O valor da penetrância da FXTAS em portadores da pré-mutação parece aumentar com o envelhecimento, sendo que mais de $50 \%$ dos pacientes do sexo masculino com mais de 70 anos apresentam sintomas da doença ${ }^{13}$.

Nos indivíduos com a pré-mutação foi observado um fenótipo molecular anormal, com níveis elevados de RNAm desse gene ${ }^{14}$. Observou-se, também, que a superexpressão do transcrito contendo a expansão CGG levava a um ganho tóxico de função desse RNA, com desregulação das células neurais, formação de inclusões intranucleares em neurônios e astrócitos e disrupção da arquitetura nuclear da laminina. A presença da FXTAS na faixa da pré-mutação e a ausência dessa síndrome nas mutações completas levou à proposição desse modelo ${ }^{15}$.

O RNAm do gene FMR1 contendo grandes conjuntos CGG recruta de maneira anormal diversas proteínas celulares, esgotando seus estoques nas células. Essas proteínas deixam de executar outras funções celulares, levando à disfunção neurológica. $\mathrm{O}$ sequestro de diversas proteínas pode levar ao acúmulo ou processamento anormal pela via de degradação proteossomal, causando a formação de inclusões celulares. Nas mutações completas, não ocorrem as interações errôneas entre RNA e proteínas devido à ausência de mRNA do gene FMR $1^{15}$.

No momento, a FXTAS é uma síndrome pouco diagnosticada, talvez pelo desconhecimento de muitos médicos, pelo fato de que suas principais manifestações podem erroneamente ser referidas como "inerentes" ao processo normal de envelhecimento ou, ainda, por assemelhar-se com outras síndromes neurodegenerativas que não possuem bases genéticas óbvias.

O objetivo do estudo foi investigar as condições clínicas e moleculares da pré-mutação do gene FMR1 em parentes de portadores da 
FRAX, uma vez que esses indivíduos apresentam alto risco de serem portadores da pré-mutação e, consequentemente, de desenvolverem FXTAS. Além disso, o estudo contribui para o melhor entendimento da síndrome entre pacientes brasileiros e, por meio da divulgação de informações sobre a mesma, contribui para que os profissionais da área de saúde tenham conhecimento acerca da FXTAS.

\section{Casuística e métodos}

Foi estruturado um banco de dados contendo 52 famílias relacionadas à pacientes com FRAX, com diagnóstico molecular da síndrome, provenientes do ambulatório de neurodificuldades da FMABC, ambulatório de genética clínica da Escola Paulista de Medicina (Unifesp-EPM) e das APAEs do Grande ABC e de São Paulo. Da casuística total, foi possível o contato telefônico com 38 famílias. Durante o contato telefônico, foi dada uma explicação breve sobre a FXTAS e foi também se questionaram o interesse e a disponibilidade do avô materno de crianças com a síndrome do X frágil em participar da pesquisa. Das 38 famílias acessadas por telefone, 15 apresentavam o avô materno vivo, mas 11 optaram por não participar da pesquisa por motivos diversos, dentre os quais o fato do familiar morar distante da FMABC (geralmente em outro Estado), questão financeira, idade avançada e ausência de sintomas (visto que se trata de uma doença de acometimento tardio).

Os pacientes foram submetidos à avaliação clínica por um neurologista em busca de sinais característicos da síndrome de acordo com os revisados por Jacquemont et al., $2007^{4}$.

A extração do DNA a partir da amostra de $5 \mathrm{~mL}$ de sangue periférico dos pacientes selecionados foi realizada utilizando-se o blood genomicPrep Mini Spin Kit (GE Healthcare), seguindo as instruções do fabricante. A subsequente análise da expansão do gene FMR1 foi reali-

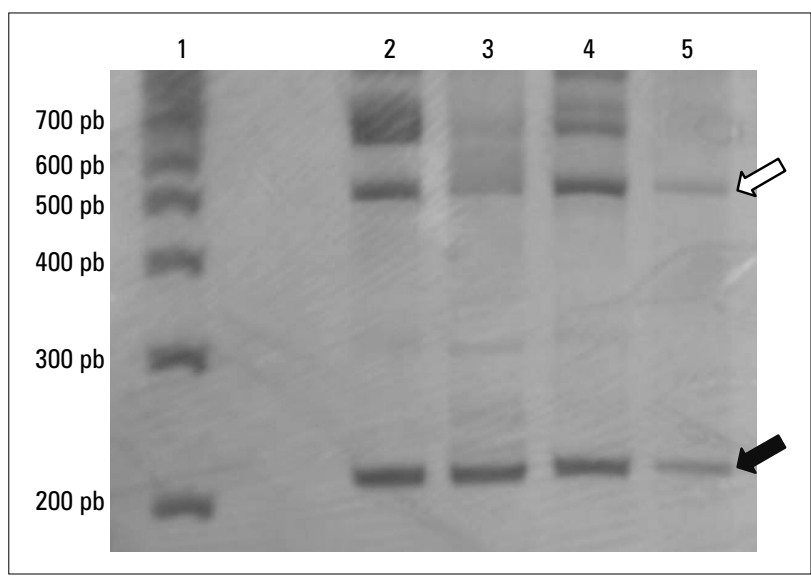

Figura 1 - Gel de poliacrilamida 12\% corado em prata. 1: marcador de peso molecular (100 pb); 2, 3, 4, 5: amostras de alelos normais, nas quais se nota uma banda de 223 pb, correspondente à amplificação de uma região fora da região de repetição considerada controle da reação de PCR (seta preta) e de uma banda maior, que pode ser de tamanho variável, pois flanqueia a região contendo as repetições CGG (seta branca) zada a partir da amplificação do DNA por reação em cadeia da polimerase (PCR) segundo o protocolo proposto por Haddad et al. (1996) $)^{16,17}$. Para tanto, foram utilizadas três sequências de primers, Eag-L (5'-cgctgcgggtgtaaacactgaaaccacgtc- $\left.3^{\prime}\right)$, Eag-U (5'-cgacctgtcaccgcccttcagccttcc-3') e f ( $5^{\prime}$-agccccgcacttccaccaccagctcctcca-3'), confeccionados de modo a permitir a amplificação em um mesmo indivíduo de um fragmento de DNA de comprimento 223 pb localizado fora da região de repetições e de um fragmento cujo comprimento pode variar entre 450 e $1050 \mathrm{pb}$, pois compreende a região variável de repetições CGG. Quanto maior a região de repetição, maior o fragmento encontrado. Propositalmente, as condições planejadas para a PCR permitem a amplificação do segmento repetitivo só em alelos normais ou pré-mutados. Para a detecção dos fragmentos amplificados, alíquotas das amostras de PCR foram submetidas à eletroforese em gel de poliacrilamida $12 \%$ não desnaturante, corado com nitrato de prata.

Este projeto foi aprovado pelo Comitê de Ética em Pesquisa da Faculdade de Medicina do ABC (CEP/FMABC) e registrado sob o número 061/2007.

\section{Resultados}

Ao todo foram realizadas quatro consultas no ambulatório de neurologia da FMABC, todas elas com os avôs maternos dos portadores da FRAX, que foram avaliados em busca dos sintomas clínicos de FXTAS. No momento da consulta também foi colhido sangue periférico desses pacientes para análise molecular.

Os sintomas mais comumente apresentados durante as quatro consultas foram paresia e/ ou parestesia de membros inferiores, dor nas pernas, agrafia e outras apraxias. Anormalidades posturais e da marcha, tremor, além de valores alterados no teste muscular foram os achados clínicos observados. Além disso, outros achados relevantes foram: apatia, irritabilidade, depressão/ansiedade, incontinência urinária, impotência, doença cardíaca congestiva e hipertensão arterial sistêmica. A idade dos pacientes variou de 57 a 75 anos.

Quanto à análise molecular do gene FMR1, nenhum dos pacientes apresentou a pré-mutação: todos os alelos tinham tamanho da repetição dentro da normalidade (Figura 1).

Na Figura 1 podem ser observados os alelos normais das amostras 2, 3, 4 e 5, nas quais é possível identificar dois fragmentos principais: o fragmento controle (seta preta) que representa a região controle presente em todas as formas de apresentação do gene (mutação completa, pré-mutação e alelo normal); e a banda de variação (seta branca), que abriga a região do alelo contendo as repetições CGG, sendo portanto de tamanho variável.

Dois dos pacientes entrevistados na consulta neurológica apresentaram sinais compatíveis com a FXTAS, porém, essa hipótese foi descartada após a avaliação molecular das amostras de sangue. Devido aos resultados negativos da avaliação molecular, os exames de imagem não foram realizados. 


\section{Discussão}

Este trabalho buscou rastrear portadores da FXTAS, que acomete indivíduos idosos portadores da pré-mutação do gene FMR1, adotandose como princípio o parentesco que esses indivíduos apresentam com os portadores da FRAX já avaliados em projeto de pesquisa prévio ${ }^{17}$. Trata-se de uma síndrome rara que afeta portadores da pré-mutação, sendo que o risco premeditado de um homem desenvolver a síndrome durante a vida é de 1:4.500 a 1:9.000 na população geral ${ }^{12}$.

Além de rastrear os pacientes, este trabalho teve como resultado a divulgação da síndrome FXTAS para os familiares de indivíduos com a síndrome do X frágil, para os clínicos e para a população em geral. Até 2001, acreditava-se que os portadores da pré-mutação não apresentam nenhum fenótipo clínico. Hoje se sabe que a FXTAS representa a forma mais grave de envolvimento clínico associado à pré-mutação dos alelos de FMR ${ }^{18}$.

Uma vez que até pouco tempo atrás se desconhecia que homens portadores da pré-mutação poderiam apresentar algum sintoma clínico, a associação de uma doença infantil como a síndrome do X frágil e uma doença de início tardio como a FXTAS não é reconhecida por muitos neurologistas ${ }^{15}$.

A presença de sintomas de FXTAS e de um familiar afetado com a síndrome do X frágil, apesar de sugerir a causa da doença, não dispensa a avaliação criteriosa clínica e molecular, pois os sintomas são comuns a outras síndromes neurológicas ${ }^{18}$. Em nossos pacientes, além das características clínicas como dificuldade na marcha, fraqueza e dor nas pernas e declínio cognitivo evidenciados durante a consulta, a idade de início da manifestação dos sintomas (55 anos) e o seu grau de parentesco com o portador da FRAX (avô materno) eram fortes demonstrativos da presença da síndrome, o que não foi confirmado pela avaliação molecular.

A penetrância de FXTAS em portadores da pré-mutação ainda não é plenamente conhecida, embora a frequência encontrada de alelos pré-mutados na população sugira que essa doença possa ter uma contribuição significativa entre os pacientes adultos com tremor e ataxia ${ }^{13}$.

Neste estudo, realizou-se o rastreamento clínico e molecular da FXTAS na região assistida pela FMABC. Uma indicação importante para famílias com a síndrome do X frágil é o questionamento sobre a presença de problemas neurológicos em todos os familiares que estão sob o risco de possuir a pré-mutação. As famílias devem ser aconselhadas sobre o risco de desenvolverem sintomas neurológicos após os 50 anos de idade. Para muitos pacientes, os sintomas iniciam-se aos 70 ou 80 anos. Para aqueles pacientes com sintomas neurológicos, a ressonância magnética e os testes neurológicos detalhados são indicados para a detecção de tremor, ataxia, neuropatia e problemas cognitivos e emocionais. $\mathrm{O}$ acompanhamento contínuo por profissionais da área de saúde e o tratamento medicamentoso podem ajudar na melhoria de grande parte dos sintomas.

Fica claro na presente investigação que o teste de DNA constitui uma importante ferramenta na detecção da FXTAS, considerando-se que essa síndrome pode ser prevista por testes de natureza molecular. A FXTAS é uma das causas mais comuns de distúrbio neurológico progressivo em homens e, devido à sua recente descoberta e à inespecificidade de sua apresentação clínica, seus sintomas podem ser erroneamente referidos como inerentes ao processo de envelhecimento.

\section{Referências}

1. Gomes-Pereira M, Fortune MT, Monckton DG. Mouse tissue culture models of unstable triplet repeats: in vitro selection for larger alleles, mutational expansion bias and tissue specificity, but no association with cell division rates. Hum Mol Genet 2001;10(8):845-54.

2. Isashiki Y, Kii Y, Ohba N, Nakagawa M. Retinopathy associated with Machado--Joseph disease (spinocerebellar ataxia 3) with CAG trinucleotide repeat expansion. Am J Ophthalmol 2001;131(6):808-10.

3. Oberlé I, Rousseau F, Heitz D, Kretz C, Devys D, Hanauer A, et al. Instability of a 550-base pair DNA segment and abnormal methylation in fragile $X$ syndrome. Science 1991;252(5010):1097-102.

4. Jacquemont $S$, Hagerman RJ, Hagerman P, Leehey MA. Fragile-X syndrome and fragile $\mathrm{X}$-associated tremor/ataxia syndrome: two faces of FMR1. Lancet Neurol 2007;6(1):45-55.

5. Verkerk AJMH, de Graff E, de Boule K, Eichler EE, Konechi DS, Reyniers $\mathrm{E}$, et al. Alternative splicing in the fragile $\mathrm{X}$ gene FMR1. Hum Mol Genet 1993;2(8):399-404.

6. Weinhausel A, Haas OA. Evaluation of the fragile X (FRAXA) syndrome with methylation sensitive PCR. Hum Genet 2001;108(6):450-8.
7. Hagerman RJ, Hagerman PJ. Fragile X syndrome: a model of gene-brainbehavior relationships. Mol Genet Metab 2001;74:89-97.

8. Amiri K, Hagerman RJ, Hagerman PJ. Fragile X-associated tremor/ ataxia syndrome: an aging face of the fragile $X$ gene. Arch Neurol 2008;65(1):19-25.

9. Brunberg JA, Jacquemont S, Hagerman RJ, Berry-Kravis EM, Grigsby J, Leehey MA, et al. Fragile $X$ premutation carriers: characteristic MR imaging fi ndings of adult male patients with progressive cerebellar and cognitive dysfunction. AJNR Am J Neuroradiol 2002;23(10):1757-66.

10. Greco CM, Hagerman RJ, Tassone F, Chudley AE, Del Bigio MR, Jaquemont $S$, et al. Neuronal intranuclear inclusions in a new cerebellar tremor/ataxia syndrome among fragile $X$ carriers. Brain 2002;125(Pt 5):1760-71.

11. Greco CM, Berman RF, Martin RM, Tassone F, Schwartz PH, Chang A, et al Neuropathology of fragile $\mathrm{X}$-associated tremor/ataxia syndrome (FXTAS). Brain 2006;129(Pt 1):243-55

12. Jaquemont S, Leehey MA, Hagerman RJ, Beckett LA, Hagerman PJ. Size bias of fragile $X$ permutation alleles in late-onset movement disorders. $J$ Med Genet 2006;43(10):804-9. 
13. Jacquemont S, Hagerman RJ, Leehey MA, Hall DA, Levine RA, etal. Penetrance of the fragile $X$-associated tremor-ataxia syndrome in a premutation carrier population. JAMA 2004;291(4),460-9.

14. Rosseau F, Heitz D, Biancalana V, Blumenfeld S, Kretz C, Boue J, et al. Direct diagnosis by DNA analysis of the fragile $\mathrm{X}$ syndrome of mental retardation. N Engl Med 1991;325:1673-81.

15. Hagerman PJ, Hagerman RJ. The fragile $X$ permutation: a maturing perspective. Am J Hum Genet 2004;74(5):805-16.
16. Haddad LA, Mingroni-Netto RC, Vianna-Morgante AM, Pena SDJ. A PCRbased test suitable for screening for fragile $X$ syndrome among mentally retarded males. Hum Genet 1996;97(6):808-12.

17. Christofolini D, Lipay MVN, Ramos MAP, Brunoni D, Melaragno Ml. Screening for fragile $X$ syndrome among Brazilian mentally retarded male patients using PCP from buccal cell DNA. Genetics and Molecular Research 2006;5(3):448-53.

18. Berry-Kravis E, Abrams L, Coffey SM, Hall DA, Greco C, Gane LW, et al. Fragile $\mathrm{X}$-associated tremor/ataxia syndrome: clinical features, genetics, and testing guidelines. Mov Disord 2007;22:2018-30. 